IRA-International Journal of Management \&

Social Sciences

ISSN 2455-2267; Vol.09, Issue 03 (December 2017)

Pg. no. 160-173

Institute of Research Advances

http://research-advances.org/index.php/RAJMSS

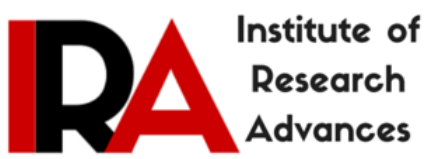

\title{
A Game-Theoretic Modelling of Risk Preferences of the Students during the Placement Process for Summer Internship, IIM Ahmedabad
}

\author{
Gautam Kumar Mandal $^{1 \#}$, Gaurav Agarwal ${ }^{2}$, Prof. Viswanath Pingali ${ }^{3}$ \\ ${ }^{1 \& 2}$ PGP, Indian Institute of Management, Ahmedabad, India. \\ ${ }^{3}$ Professor Economics Area, Indian Institute of Management, Ahmedabad, India. \\ \# corresponding author. \\ Type of Review: Peer Reviewed. \\ DOI: http://dx.doi.org/10.21013/jmss.v9.n3.p5 \\ How to cite this paper: \\ Mandal, G.K., Agarwal, G., Pingali, V. (2017). A Game-Theoretic Modelling of Risk Preferences of \\ the Students during the Placement Process for Summer Internship, IIM Ahmedabad. \\ IRA-International Journal of Management \& Social Sciences (ISSN 2455-2267), 9(3), 160-173. \\ doi:http://dx.doi.org/10.21013/jmss.v9.n3.p5
}

(C) Institute of Research Advances.

(cc) BY-No

This work is licensed under a Creative Commons Attribution-Non Commercial 4.0 International License subject to proper citation to the publication source of the work.

Disclaimer: The scholarly papers as reviewed and published by the Institute of Research Advances (IRA) are the views and opinions of their respective authors and are not the views or opinions of the IRA. The IRA disclaims of any harm or loss caused due to the published content to any party.

Institute of Research Advances is an institutional publisher member of Publishers Inter Linking Association Inc. (PILA-CrossRef), USA. The institute is an institutional signatory to the Budapest Open Access Initiative, Hungary advocating the open access of scientific and scholarly knowledge. The Institute is a registered content provider under Open Access Initiative Protocol for Metadata Harvesting (OAI-PMH).

The journal is indexed \& included in WorldCat Discovery Service (USA), CrossRef Metadata Search (USA), WorldCat (USA), OCLC (USA), Open J-Gate (India), EZB (Germany) Scilit (Switzerland), Airiti (China), Bielefeld Academic Search Engine (BASE) of Bielefeld University, Germany, PKP Index of Simon Fraser University, Canada. 


\begin{abstract}
The placement process for summer placements at IIM Ahmedabad renders a series of decisions to be judiciously taken by every student owing to the limited time availability and a highly competitive environment. In this paper, we have primarily analysed the period between the day students of first year management programme have their CVs frozen (cannot be altered later) and the day the last student of the batch gets an internship offer. The dilemmas faced by a student are dependent on their personal profile but also largely on the sequence of events unfolding during the period. Using the publicly available data of last two years' summer placements, a survey administered to second year students, long form conversational interviews (LFCI) with concerned office bearers over the last one month, and the previously established econometric models for utility derived in various human activities as given in literature have been quantitatively and qualitatively analysed and combined together to generate a set of inequalities attempting to resolve the dilemmas that students face. The various decisions are considered as subgames in a decision tree, and have been solved using the inequalities developed. Significant insights about the proposed rational behaviour has been drawn and interpreted back in nonmathematical terms in the end. In an attempt to maximise the various utility functions, some of the variables have been taken as categorical predictors providing a discrete description of the placement process. Overall, the paper attempts to give a systematic method of analysing and recommend the decisions a rational student should optimally take during the three months period of excessive work load, and high stakes.
\end{abstract}

KEYWORDS: Decision Making, Risk Preference, Statistical Model, Nash Equilibrium

\title{
INTRODUCTION
}

The summer internship process at IIM Ahmedabad is considered as a highly disciplined, time-constrained and rigorous exercise for the first year students of the flagship two-year management programme. Students at the premier institute need to start planning about their summer placements as soon as just one months within their admission, with the submission deadlines for the final unalterable version of resume being generally around August 15, nearly two months after the term starts for the new joiners. In this paper we aim to investigate the process in which a particular student can optimise her time allocation for preparation for placement in companies of her choice, and resolve various dilemmas originating due to trade-offs like increased chance of selection by applying to a number of firms, but decreased quality of submitted applications \& firm-specific preparation if she applies to a large number of firms.

Let us first try to qualitatively understand the time constraints that a student of first year management programme goes through during the preparation phase, i.e. during approximately three months before the summer placement dates (which generally occurs in first week of November). Specifically, the time range for our analysis is between the day CV freezes (which has been assumed as August 15), and the day summer placement ends i.e. last cluster ends with the last student of the batch getting placed (which has been assumed as November 15). The time available with a student during the preparation phase is limited, and can be broadly allocated to these activities:
(a) Academic activities \& courses
(b) Preparation for summer placements
(c) Club activities \& Competitions
(d) Leisure, recreational \& personal activities

In the above segmentation, the portion of God's hour of time which is essential for daily human body requirements, like sleep and maintaining personal hygiene have been ignored, and hence in our analysis, the sum of time taken for the above four segments shall be less than the total available time which is God's our minus the time required for basic human body requirements. It is intuitive to claim that the general trend of the level of performance obtained in all these four sets activities (except for leisure activities, where we consider utility derived from them as an indicator of performance) with respect to the inability to devote time to that particular activity shall follow a trend similar to what has been shown in the curve below. It is a general adaptation of the concept of diminishing marginal returns. This has to be kept in mind while we generate the model for the complete analysis of the impact of time allocation differences. The graph shown below is a polynomial function, however, a similar logarithmic function could have been used as well. An inherent assumption in the analysis is that when a student decides to invest a particular amount of time for any activity, he or she executes the activity without any interruption or diversion of attention from the activity, since we are investigating the case for highly motivated and high-performing individuals of the premier institute. 


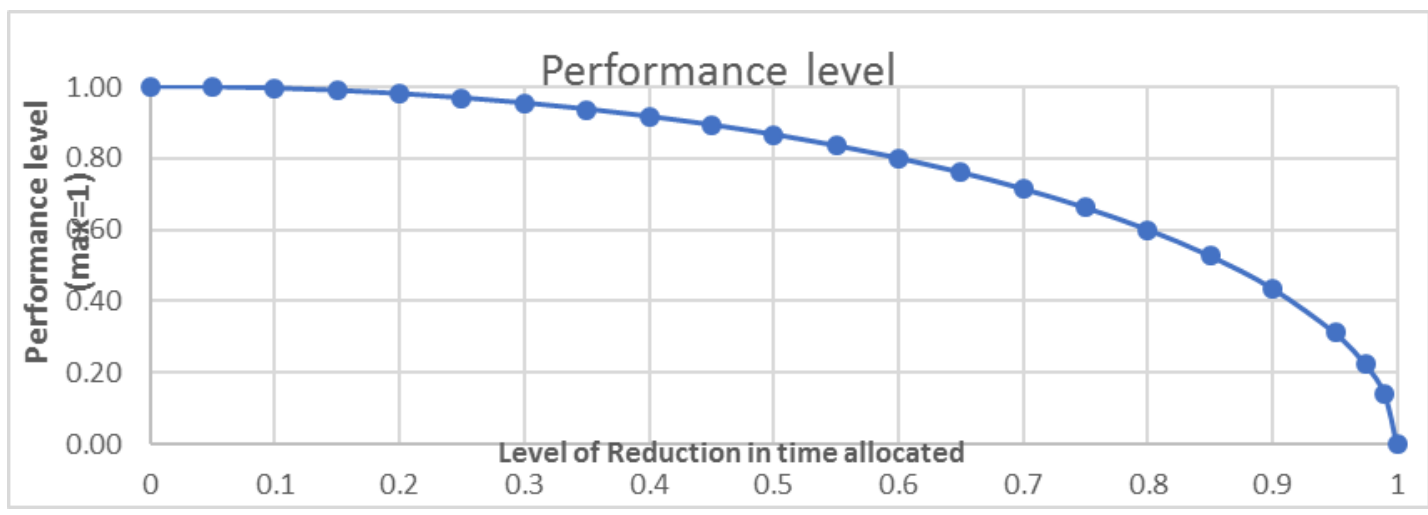

Dilemmas: We have identified five types of dilemmas or decision points that a student encounters in his or her preparation phase. In the final model built by us, to maximize the overall utility of any candidate, we shall incorporate the impact of all these five decision points as predictor variables.

Decision 1: Should we fill all the available forms (i.e. should one apply for all the firms)? If not, then what should be the basis for leaving out on applications? A student may leave filling forms of reputed but difficult to join firms, or of less reputed but easier to join firms (i.e. so called 'not so good' firms), or all firms of a particular sector, or as per the amount of expected time for the firm specific preparations.

Decision 2: Which all cohorts (marketing, finance, consulting, general management, others) should I prepare for? A student may decide to prepare for all cohorts, or choose to focus on just one or two of these. It is well understood that different firms that come under same cohort generally require similar type of preparations, but two firms picked from two different cohorts shall require completely different type of preparations. The decision regarding selecting to prepare for just one or two cohorts is generally backed by the personal profile and abilities of a candidates as well as her perception about the chances of her selection in a particular cohort. Note that the abilities of the candidates mean their relative strength which is a result of their past experiences and natural talent, and is not same as the capabilities acquired by them by investing more time in preparations. A student may be risk averse and may not risk leaving any opportunity, hence apply for all cohorts by spreading her preparation time and efforts to all the cohorts, rather than concentrating heavily on just one or two.

Decision 3: Which particular firm should be my first priority? This includes the decision about firm specific preparations. A student may choose to prioritise a company based on her knowledge about that company, or her perceived fit (Human resource based aspects like similar values) with the company. This means that she will decide to invest more time in preparations for such firms. Similarly, having proficiency in similar functional area which a particular firm is offering (e.g. a student with expertise in digital marketing may value a firm offering digital marketing roles more) may impact the decisions of a student. However, choosing to invest more time in firm specific preparations comes with an added risk of missing out on the preparations for many other firms or a cohort. Also, many students want to broaden their area of expertise by applying for firms with kind of roles which they are yet to experience, and assuming that they would be able to perform reasonably well in the others.

Decision 4: Should I participate in cluster-1 or not? Actual summer placement dates at IIMA are divided into 3 clusters and a rolling round. Cluster-1 (or the day 0 \& day 1) generally includes consulting and finance firms visiting the campus. Cluster-2, which occurs after Cluster-1 is over, generally includes marketing and general management firms. We have assumed Cluster-3 and an optional rolling round to account for all the other types of firms. Now the decision dilemma that a student faces is whether or not to participate in Cluster-1. If she is hopeful that she is most likely to get placed in Cluster-2, based on her preparations \& profile, then she might choose not to participate in Cluster-1 as it will hamper her actual performance in Cluster-2 due to fatigue because of the highly strained and fast-paced requirements of the process. It will also deprive her to be able to invest any time for preparations for her Cluster-2 firm during the peak period. Peak period has been defined as a time frame of 2-4 days the day before a candidate has to appear for an actual interview, where she needs to involve herself in all sorts of relevant documentation, revision, and firm dependent personalisation works. However, participating in cluster-1 shall definitely provide her an increased opportunity to get placed in reputed firms in a quicker time, and be able to be remaining in the zone of mental strain for less length of time. It is interesting to note that, even if a student prefers only cluster-1, she may have to appear for cluster-2 in case of not being able to get placed during cluster-1. However, if a student prefers only cluster-2 and cannot get placed, she cannot go back and appear for the cluster-1 firms. This also adds more complexity to the decision that a student has to take, as discussed mathematically later in the paper. 
Decision 5: How to allocate time between academics, placement preparation, competitions/club works and Leisure? These four categories have been explained above, and a student needs to figure out the relative amount of time allocation which is best suitable for him. Here, the goal is to get placed in the best possible firm, and the optimisation has to be centred around this goal only.

\section{Building the Mathematical Model}

We now aim to enter the step by step process to generate mathematical behaviour of all these decisions, and then merge all of them to get a mathematical model for the entire placement process. The model should maximize the overall utility which comes from getting placed in the best possible firm from the institute, which in turn depends of many parameters, one of which is the maximum possible utility derived from getting placed in the best possible firm during the summer internship.

In that regard, let us first analyse a student's relative strength for each of the companies in which he is eligible to apply for. At the outset, for a large number of available company $(n>30$ has been considered as sufficiently large number based on normal statistical analysis which shall be followed in this paper) the strength of the candidate shall appear as a set of random numbers varying from 0 to 100 , where 100 means he is the $100^{\text {th }}$ percentile $\left(1^{\text {st }}\right.$ rank) in the batch for that $i^{\text {th }}$ company. Similarly, a value of 60 means he is in the $60^{\text {th }}$ percentile i.e. better than 60 percent of the batch as far as the strength for selection that particular firm is concerned. Here, where $\mathrm{i}=1,2,3 \ldots \mathrm{n}$; where $\mathrm{n}$ is the number of companies available to the student (assumed same for the whole batch, as the sample set of firms is available for each student.)

Now one may argue that some firms require mandatory 2 years' professional experience and so on, and thus the fresh undergraduates do not have those firms available to them; and hence for them the number of firms available should be considered less than n; however, our model shall assume that this only means that the firm is available to the student but his/her relative strength in that firm is zero. This means all students shall have $n$ firms available to them.

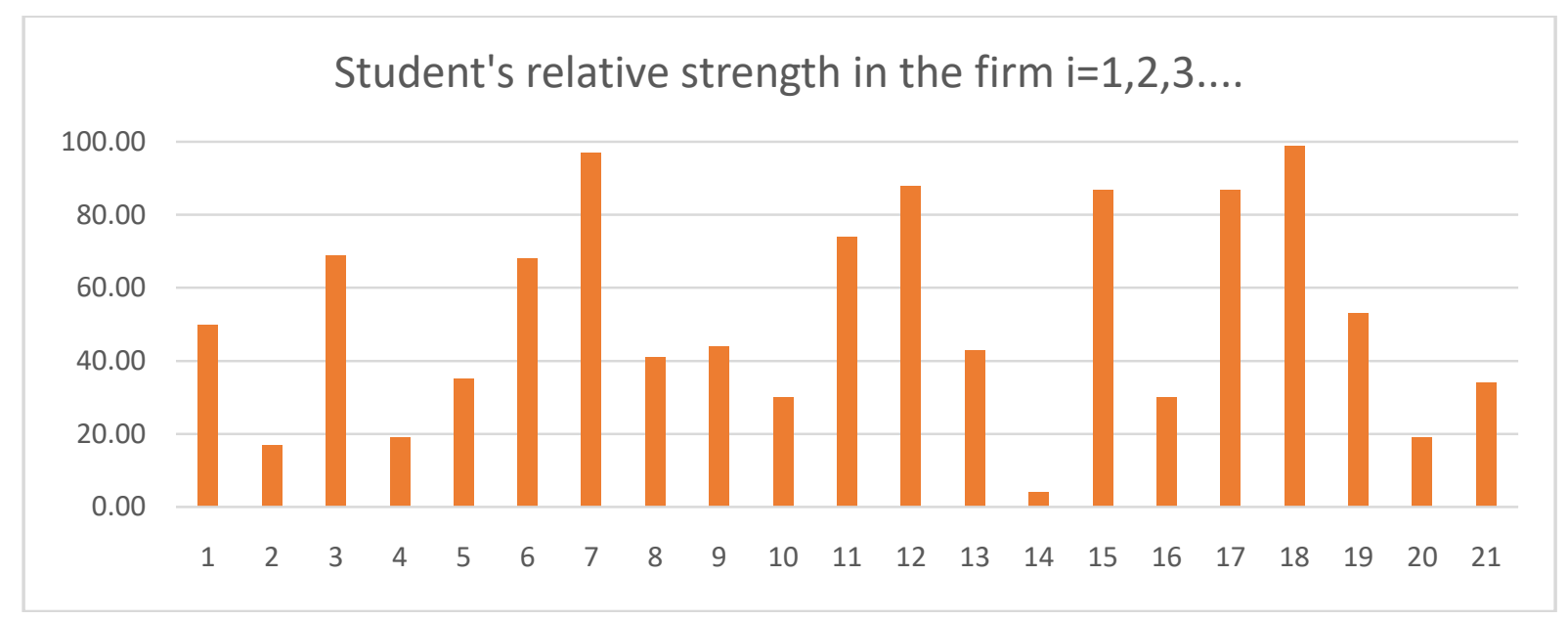

Note that this representative graph is for one student alone, and there would be similar graphs for all the students for the set of all possible companies. Now onwards, unless otherwise mentioned we shall conduct the analysis from the point of view of a single student, and find out how he or she can optimise his or her choices at each stage. Of course based on the associated coefficients and factors, this optimisation exercise would vary for every student.

For a student, his ultimate aim is to maximise his overall utility by getting placed in the best possible firm at IIMA. Let this be utility be denoted as $U_{j}$ (later written as just $U$ in student specific analysis).

Then $\mathrm{U}_{\mathrm{j}}=\mathrm{f}$ (the company that one finally gets placed in $)=\mathbf{f}(\mathbf{g})$

i.e. the ultimate objective is to maximize $\mathbf{f}(\mathbf{g})$ or $\mathbf{U}_{\mathbf{j}}$.

Note that the ' $\mathrm{g}$ ' as mentioned above is itself a function of many other factors. One of the main factors shall be the company in which the student does his summer internship. Hence, the core of our analysis remains to be evaluating from a game-theoretic perspective, a method to get the best possible summer internship. Other factors that shall be acting as predictor variables have been explained in the function below.

Here, analysed period refers to the period of 90 days from $15^{\text {th }}$ August to $15^{\text {th }}$ November, which is the duration between the day CVs are frozen and the day summer placements end. 
Now, $U_{j}=f(g)=f(g)$ where student $j$ interns, academic performance of $j$ during the analysed period, performance of $\mathrm{j}$ in case competitions and club activities during the analysed period, factors dependent on the student $\mathrm{j}$ but outside the analysed period (such as performance in summer internship, academic performance after analysed period and up-to term 5, performance in competitions after analysed period etc.), $\overline{\text { uncontrollable exogenous factors e.g. health }}$ )

Note that the function ' $\mathrm{g}$ ' has been shown to be a function of five factors above. Out of these five factors, two have been written with a $\overline{\boldsymbol{b} a \boldsymbol{r}}$ overlined above them, which means that they are outside the control of students viewing from the frame of the analysed period, and hence have been taken as given for the decision making which has to happen during the analysed period and not later.

Before we start writing exact notations for the above function, we would like to drill down a bit on its components as well in a similar fashion. The five components of the function ' $\mathrm{g}$ ' have been described below.

1. Where student $\mathbf{j}$ interns $=\mathrm{f}$ (frozen $\mathrm{CV}$, number of students applying to different companies $\mathrm{i}=1,2,3, \ldots \mathrm{n}$, preference order of companies for each student including student $\mathrm{j}$, expected number of seats offered by different companies $i=1,2,3, \ldots n$, whether student $j$ applied to company $i$ or not, student j's overall preparation time devoted for company i's specific preparation, j's time devoted for preparation of cohort $\mathrm{k}$, student $\mathrm{j}$ 's relative ability \& strength for cohort k excluding (minus) her frozen $\mathrm{CV}$, overall leisure time which holistically improves my performance and well-being Error! Bookmark not defined., availability of time for placement preparation and rest during the peak period).

There are two points worth mentioning here. Firstly, we have not taken the actual performance on D-day (interview day) as a predictor because those have been considered as uncontrollable factors, and hence have already been included in the exogenous factors. Secondly, the rare case where a student has got any PPI (pre-placement interview call) because of winning any competition, has been ignored here. The reason is that the number of such students is very less and ignorable.

2. Academic performance in the analysed period $=\mathrm{f}$ (actual performance in individual evaluation which in turn depends on j's time devoted to academics and j's relative strength in the academic courses, actual performance in study group tasks which in turn depends on the time devoted by $\mathrm{j}$ to group tasks and time devoted by other members to group tasks and also the relative strength of the group).

Note that here an inherent simplifying assumption is that the time devoted by me is unrelated to time devoted by others in any particular activity.

3. Performance in club activities or competitions $=f$ (time devoted by student $j$, j's relative strength which is highly contextual).

4. The fourth predictor was constant and it will not be written in a functional form, as those are factors dependent on the student $\mathrm{j}$ but outside the analysed period .

5. Similarly, the fifth predictor was constant and it will not be written in a functional form, as they are uncontrollable exogenous factors e.g. health which cannot be predicted during the analysed period.

Now that we have written all the functions in plain language and shown the predictors on which their behaviour is supposed to depend, it is imperative that the mathematical notations are introduced so as to be able to analyse them further. Let us start from examining the behaviour of all these functions. The behaviours have been finalised as shown in the formulations and graphs represented below. This has been done based on 3 LFCI (long form conversational interview with placement committee members), 1 FGD (focussed group discussion of 9 students being remotely observed), and one survey administered to 38 second year students of IIMA, who have already and recently undergone through the whole process of summer internship.

Most of the scatter plot based on the quantitative data collection by surveys turned out to be highly unarranged without display of any strong trend, and $\mathrm{R}^{2}$ values for any common logarithmic, exponential and simple polynomial fit were poor. However, each of these scatter plots could be taken iteratively with the best $\mathrm{R}^{2}$ curve first and then merged with our qualitative understanding of the practical process. If there was a logical coherency between the two behaviours, the scatter plots were accepted, and then validated from similar analysis in existing literature. However, if there were logical inconsistencies between the two behaviours, we moved to the next best $\mathrm{R}^{2}$ curve. 


\section{Empirical formulation of Utilities}

After all the curves were finalised, we checked for the logical consistency of the effects produced by combinations of such behaviours, which were again validated by drawing analogies with instances in the established secondary literature in the field of economics and econometric analysis (such as econometric model for choice between products), as there is no direct literature developed on this subject matter yet.

Let us first define some of the key notations as below.

\section{$U=$ The overall utility by achieving the final goal of getting placed in the best possible firm}

$\Gamma_{1}=$ The utility derived by where a student $\mathrm{j}$ interns

$\Gamma_{2}=$ The utility derived by the academic performance in the analysed period

$\Gamma_{3}=$ The utility derived by $\mathrm{j}$ 's performance in competitions (c), and club activities (l)

$\mathbf{U}\left(\mathbf{T}_{\mathbf{u}}\right)=$ The utility derived from the leisure time which is positive for the overall utility, however, it may go against the time constraint and may cause other negative impacts on correlated variables.

Remember that each of the $\mathbb{\Gamma}_{1}, \mathbb{\Gamma}_{2}$, and $\mathbb{\Gamma}_{3}$, are in functions of their respective sets of variables with different behaviours which we are interested in investing. The method of zeroing down on the behaviours of the variable is the iterative method as explained above. For once, let us assume that we could finalize the behaviour of all those variables, which shall be later explainedin detail. As such, once we have the finalised behaviours of the variables known, their appropriate combinations can be used to build an empirical model for the utilities $\mathbb{\Gamma}_{1}, \mathbb{\Gamma}_{2}$, $\mathbb{\Gamma}_{3}, \mathrm{U}\left(\mathrm{T}_{\mathrm{u}}\right)$ and $\mathrm{U}$.

The model obtained for the above-mentioned utilities are as given below.

$$
\text { Overall Utitlity, } \quad \boldsymbol{U}=\mathbb{\Gamma}_{1}+\mathbb{\Gamma}_{2}+\mathbb{\Gamma}_{3}+\boldsymbol{U}\left(\boldsymbol{T}_{u}\right)+\boldsymbol{E}
$$

The overall utility, of course is the sum of all the component utilities identified.

$$
\mathbb{\Gamma}_{3}=\left[a_{3 c}\left(e^{T c}-1\right)+a_{3 l} T_{l}\right]
$$

This basically shows the utility derived from the competitions (c) and clubs (1). For competitions, the utility has been found to be increasing with the time invested in the activity, however, the marginal benefit is considered very low for initial few hours of investment of time and it goes on increasing as more and more number of hours are dedicated to the competitions. Also, it has historically been seen that in most cases. To validate this, we approached 16 winners of case competitions and talked to them. 81.25\% respondents agreed that as they invested more and more time, the quality of their work improved exponentially because the initial time for cracking the core of case was very large, however, once the cases got cracked it was just a matter of analysing the case from various established frameworks, and they could just go on with an accelerated analysis.

For club related works, the output is in form of CV points for next year and interpersonal skills development, as accepted by people in the FGD. This is perceived to be increase linearly with the amount of time invested to the club related works. If someone invests no time at all, then he has no advantage as such because the club entry points are already taken into account in the frozen $\mathrm{CV}$, and any extra value would be added only if the person works for the club.

$$
\mathbb{\Gamma}_{2}=\left[a_{g 1}+a_{g 2} \log \left(1+T_{g}\right)+a_{I} \log \left(1+T_{I}\right)\right.
$$

The utility function for the academic performance, as qualitatively explained earlier, depends only on two variables, while all other predictors are constant for us and can be subsumed in minimum number of constants as coefficients $a_{g 1}, a_{g 1}$ etc. The two predictors variables for academic performance are the actual performance in individual evaluation which in turn depends on $\mathrm{j}$ 's time devoted to academics $\mathrm{T}_{\mathrm{I}}$, and actual performance in group evaluation which in turn depends on time devoted by the group to academics $\mathrm{T}_{\mathrm{g}}$. The behaviour have been obtained to be logarithmic based on the approach explained above, and explained by scatter plots later. Logarithmic behaviour follows the diminishing marginal return behaviour with the time invested. It is worth noting that natural logarithmic function would become infinitely negative (or undefined) if the time invested were zero, however, in the statistically controlled empirical formula, the use of argument $\left(\mathbf{1}+\mathbf{T}_{\mathrm{g}}\right)$ for $\log _{\mathrm{e}}$, instead of simple $T_{g}$, not only resolves that issue, but ensures that it defines a behaviour that is practically observable in real-life.

The empirical equation for the utility derived by interning in a particular company $\mathrm{i}$ is slightly complex because it has many active variables. This utility has been denoted as $\mathbb{\Gamma}_{1}$ and encompasses four major terms as shown below.

$$
\mathbb{\Gamma}_{1}=\frac{\left[\left(D_{4}\left[\sum b_{1 i} D_{1 i} \log \left(1+T_{1 i}\right)\right] *\left[\left(P_{1}+Q_{1}+K_{1}\right)^{\frac{1}{3}}+K_{2}\right]\right)\right]}{(P+Q)_{\max }}
$$




$$
\begin{aligned}
& +\frac{\left[\left(D_{4}\left[\sum b_{2 i} D_{2 i} \log \left(1+T_{2 i}\right)\right] *\left[\left(P_{2}+Q_{2}+K_{3}\right)^{\frac{1}{3}}+K_{4}\right]\right)\right]}{(P+Q)_{\max }} \\
& +\frac{\left[\left(\left[\sum b_{3 i} D_{3 i} \log \left(1+T_{3 i}\right)\right] *\left[\left(P_{3}+Q_{3}+K_{5}\right)^{\frac{1}{3}}+K_{6}\right]\right)\right]}{\left(1+D_{4}\right)^{\alpha}} \\
& +\frac{\left[\left(\left[\sum b_{4 i} D_{4 i} \log \left(1+T_{4 i}\right)\right] *\left[\left(P_{4}+Q_{4}+K_{7}\right)^{\frac{1}{3}}+K_{8}\right]\right)\right]}{\left(1+D_{4}\right)^{\alpha}}
\end{aligned}
$$

The first two terms are related to the utilities derived from cluster 1, while the remaining 2 are from cluster 2 . As we have focussed only on 4 cohorts ( 2 in each of these clusters), and ignored other cohorts which belong to cluster-3 as discarded firms (even though it is not necessarily the case always), we may assume the utility by those firms to be zero or negligible. $(\mathrm{P}+\mathrm{Q})_{\max }$ in the above formula is the total number of hours one can stretch a particular activity to, which will be equal to Gods hour minus sleep time in simple terms. In theory, a person could use all the other times just for preparing for one particular cohort.

In case we believe that a person can work for maximum 16 hours a day, then in the 90 days window of analysed period, the value of $(\mathrm{P}+\mathrm{Q})_{\max }$ in hours would be $\mathbf{1 6 \times 9 0}=\mathbf{1 4 4 0}$ hours. This $(\mathrm{P}+\mathrm{Q})_{\max }$ has been used to normalise the terms of cohort preparation times e.g. $\mathrm{P}_{1}$ (before shortlist comes) and $\mathrm{Q}_{1}$ (after shortlist comes), which are already multiplied by another function of time based on the sum of company specific preparations i.e. $\left[\sum b_{1 i} D_{1 i} \log \left(1+T_{1 i}\right)\right]$. Here, $\mathrm{T}_{1 \mathrm{i}}$ is the time invested by student $\mathrm{j}$ on company specific preparations for the firm $I$, while $D_{1 \mathrm{i}}$ is an indicator variable which takes value as following:

$$
\begin{aligned}
& D_{1 i}=1 \text {, if the forms of cohort } 1 \text { firms have been filled } \\
& 0, \text { otherwise }
\end{aligned}
$$

The constant $b_{1 i}$ is takes care of the relative positioning or strength of a candidate among those who apply for a particular firm, and factors such as risk preference of the candidate. This shall be different for each firm and hence, a summation has been taken over $i$ to get the net utility values. Note that the process of normalisation not only help preserve the dimensional homogeneity if at all it was going to get violated, but also prevents the utilities getting squared.

The factor $\mathrm{D}_{4}$ is extremely critical as it relates to the decision 4 mentioned in the beginning of this paper. It tells whether or not to participate in cluster-1. This can be viewed as a case of sub-game perfect Nash equilibrium, as this decision comes at the end of the chain and is contingent on all the decisions taken in other stages of the decision tree. This has been analysed in detail in the next section. $\mathrm{D}_{4}$ must be taken as 1 if the candidate chooses to participate in cluster-1, hence its usage in the first and the second term of the equation for $\mathbb{\Gamma}_{1}$ is simple i.e. $D_{4}\left[\sum b_{2 i} \ldots \ldots\right.$ form

but not so simple in case of the third and the forth term, where a candidate may choose to participate in cluster-2 even after appearing in cluster-1 but his chances shall be lesser due to diverged attention and energy, lack of rest during the peak period etc. Hence the utilities have been divided with a factor of

$\left(1+D_{4}\right)^{\alpha} \ldots \ldots \ldots$.... form,

which shall be $2^{\alpha}$ is the candidate chooses to appear in both the clusters. The scatter plots all the empirical behaviors which have been generated by survey results based on quantitative survey questionnaire administered to the second year students (e.g. how many hours did you prepare for cluster-1 firms), shall be explained putting more light into the empirical formulation for $\mathbb{\Gamma}_{1}$.

$$
\text { Also, } \quad U\left(T_{u}\right)=a_{u} \log \left(1+T_{u}\right)
$$

And, $\quad \boldsymbol{E}=$ adjustor error term, which also incapsulates time constraints within itself

Where $\boldsymbol{U}\left(\boldsymbol{T}_{\boldsymbol{u}}\right)$ is representative of the positive influence on the candidates overall performance, if he or she is able to enjoy an adequate leisure time also. This function may look little confusing as it says that with increasing $\mathrm{T}_{\mathrm{u}}$ the utility keeps on increasing. It is worth mentioning that the behaviour is true, but as one invests more time in $\mathrm{T}_{\mathrm{u}}$, due to time constraints he or she misses out on investing the available time on more powerful functions with bloated coefficients e.g. time dedicated to club works.

The scatter plots used in our analysis have been displayed below. These plots, generated by survey data, are loosely matching with the expected trend in some of the cases. It is expected that if there would be large number of participants $i$ the survey, the trend would be refined and closer to the stated functions. To special interest is the graph for cohort preparation which was later verified from the participants of the FGD. It was discovered that participants feel that initially they can learn quickly about the cohort with minimum effort and time. As they want to invest more time into preparation for the cohort, the learnings multiply, and because the information is 
generic and useful for so many firms, the learning process and the expected utility increases rapidly. However, after a certain level of preparation, redundancies start coming in. That is shown by a point of inflexion and then decelerated growth of the utility function. There arises a need to look into company wise details for firms belonging to a particular cohort, and I someone still continues investing more time, the utility growth becomes almost stagnant. This behavior is similar to cube-root (power 1/3) function as written in the formula above as well. Let us first see the scatter plot for relative increase in utility from group evaluation wit increase of time invested $\mathrm{T}_{\mathrm{g}}$.

An important point to remember the time constraints while analysing any individual utility-time graph. Hence, all the above equations are subject to this constraint:

Time required to fill the forms of companies + Time devoted to firm specific preparations + Time devoted cohort specific preparations + Time devoted to individual evaluation + Time devoted to group tasks + Time devoted to clubs + Time devote to competitions + Liesure time $=$ Total time available for allocation during analysed period (God's hour - sleep etc) i.e.

$\sum \mathbf{d}_{\mathrm{i}} \mathbf{D}_{\mathrm{ki}}+\sum \mathbf{T}_{\mathrm{i}}+\sum \mathbf{P}_{\mathrm{k}}+\sum \mathbf{Q}_{\mathrm{k}}+\mathbf{T}_{\mathrm{g}}+\mathbf{T}_{\mathrm{I}}+\mathbf{T}_{\mathrm{c}}+\mathbf{T}_{\mathbf{l}}+\mathbf{L}\left(\mathbf{T}_{\mathrm{u}}\right)=\mathbf{T}_{\text {allocation }}=\mathbf{T}_{\mathrm{Gods}}-\mathbf{T}_{\text {sleep,hygiene }}$

Keeping this constraint in mind, the scatter plots based on the data collected from the surveys have been analysed further.

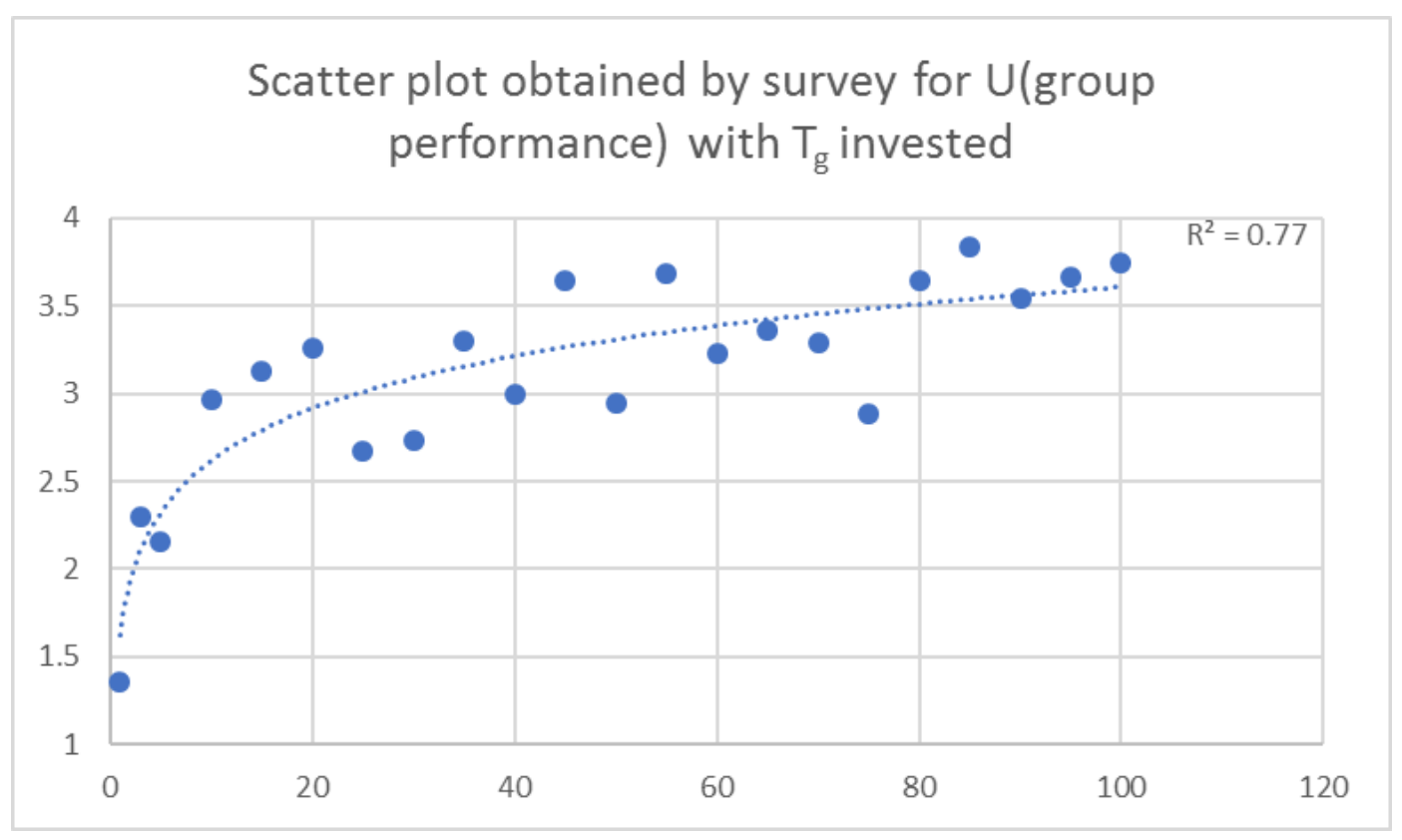

A similar behaviour but with more scatter was observed in the data obtained for individual performance.

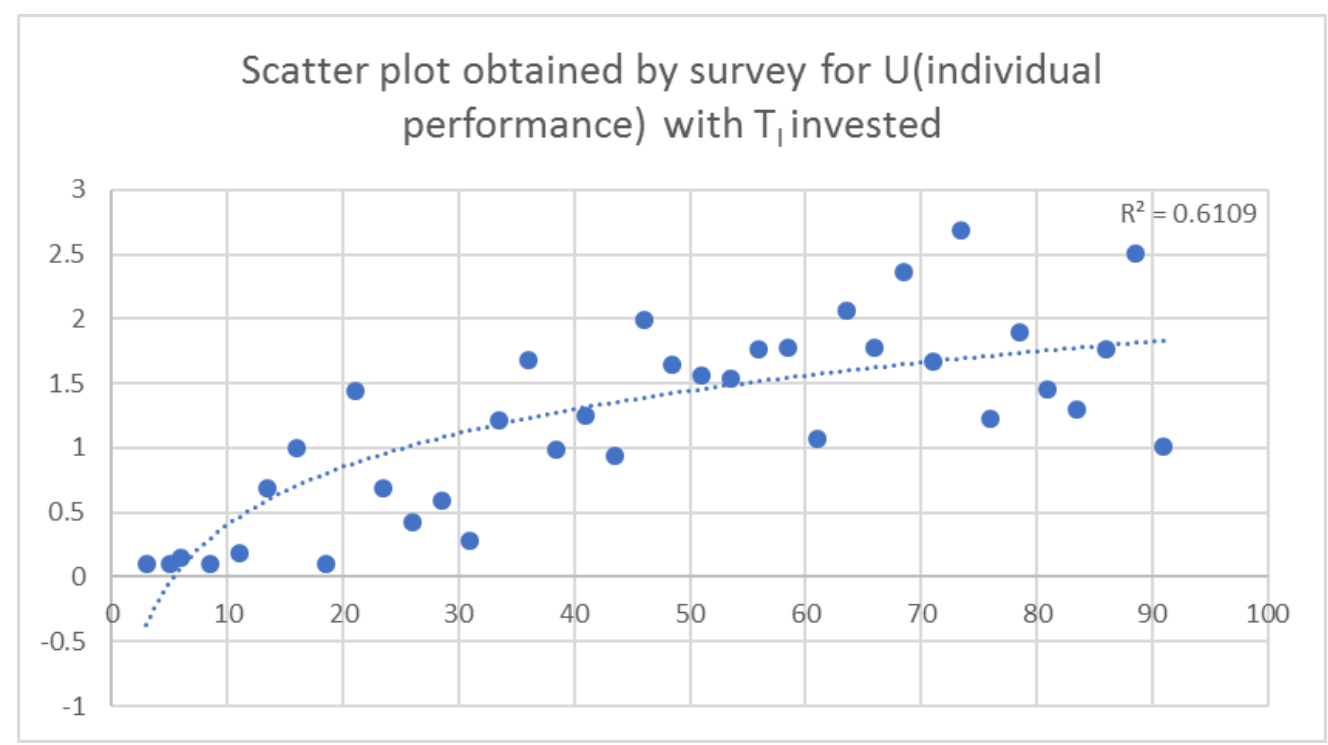


For competitions, the quality of output and chances of winning increase very rapidly once candidate start investing more time.

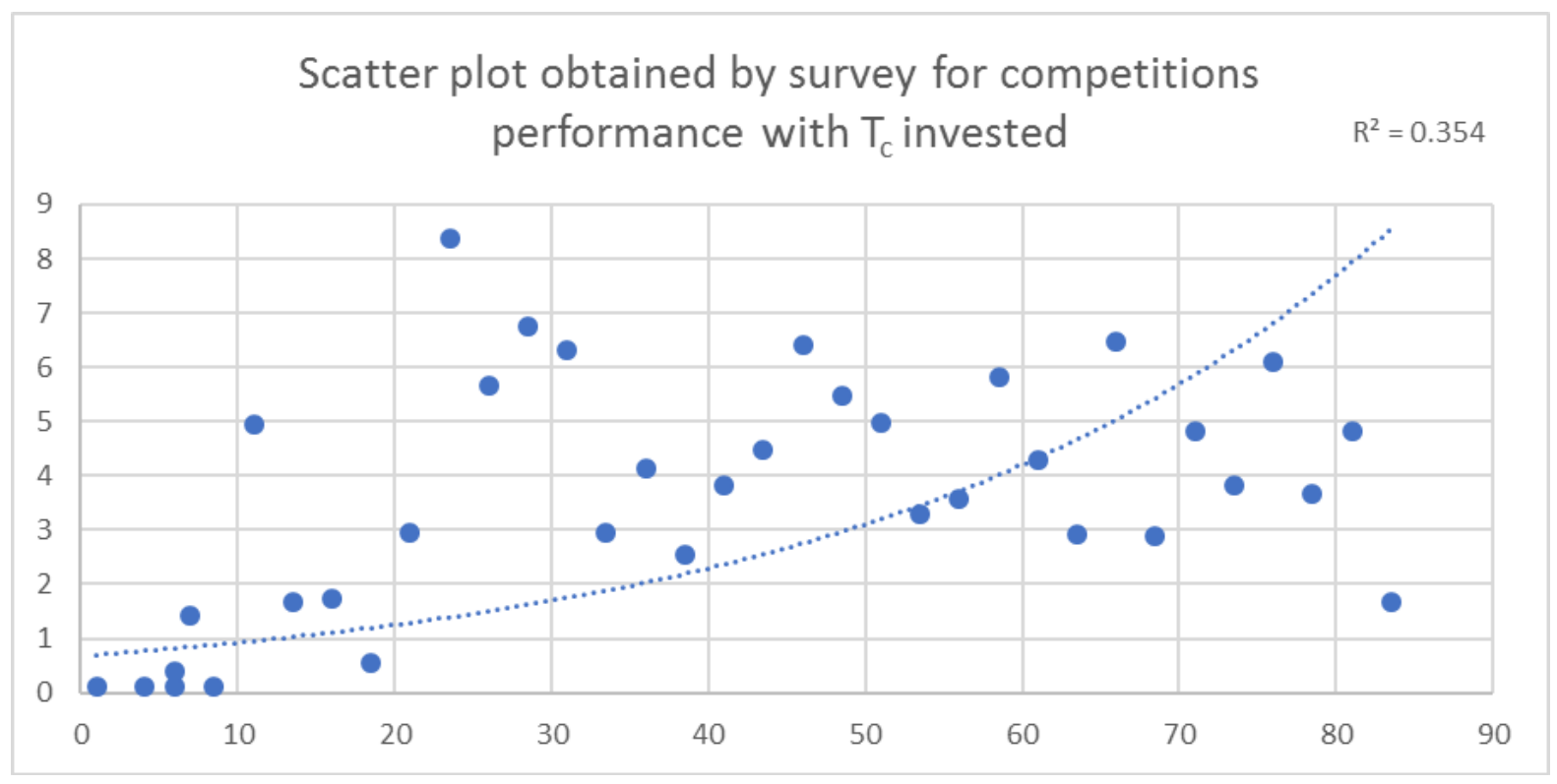

For club works, the difference in the perceived status of the clubs comes into play, and no definitive trend can be observed. However, students during the FGD felt that club work proportionally influences our career benefits.

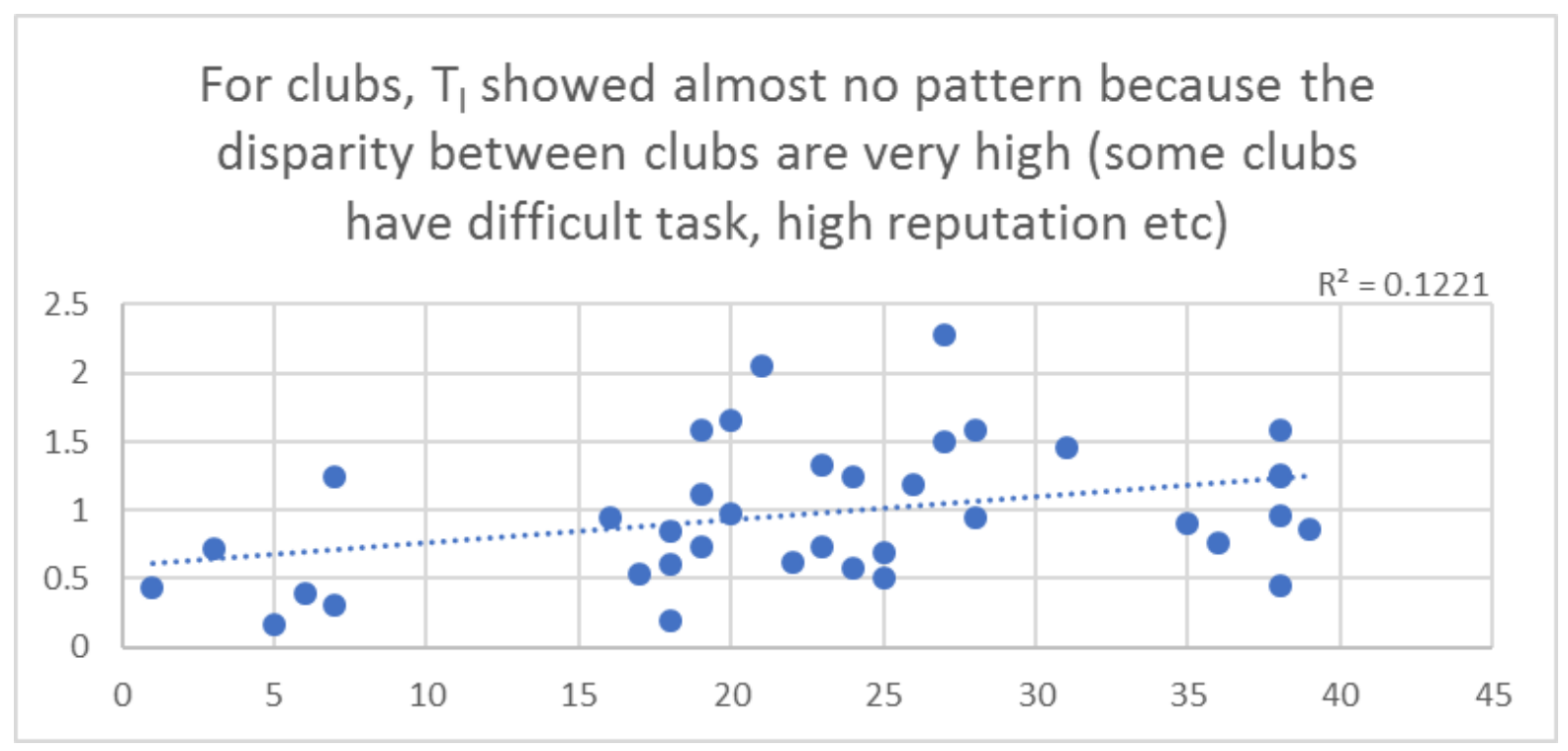

Cohort preparation time and its effect are interesting as explained above. After a certain level of preparation, redundancies start coming in. That is shown by a point of inflexion and then decelerated growth of the utility function. 


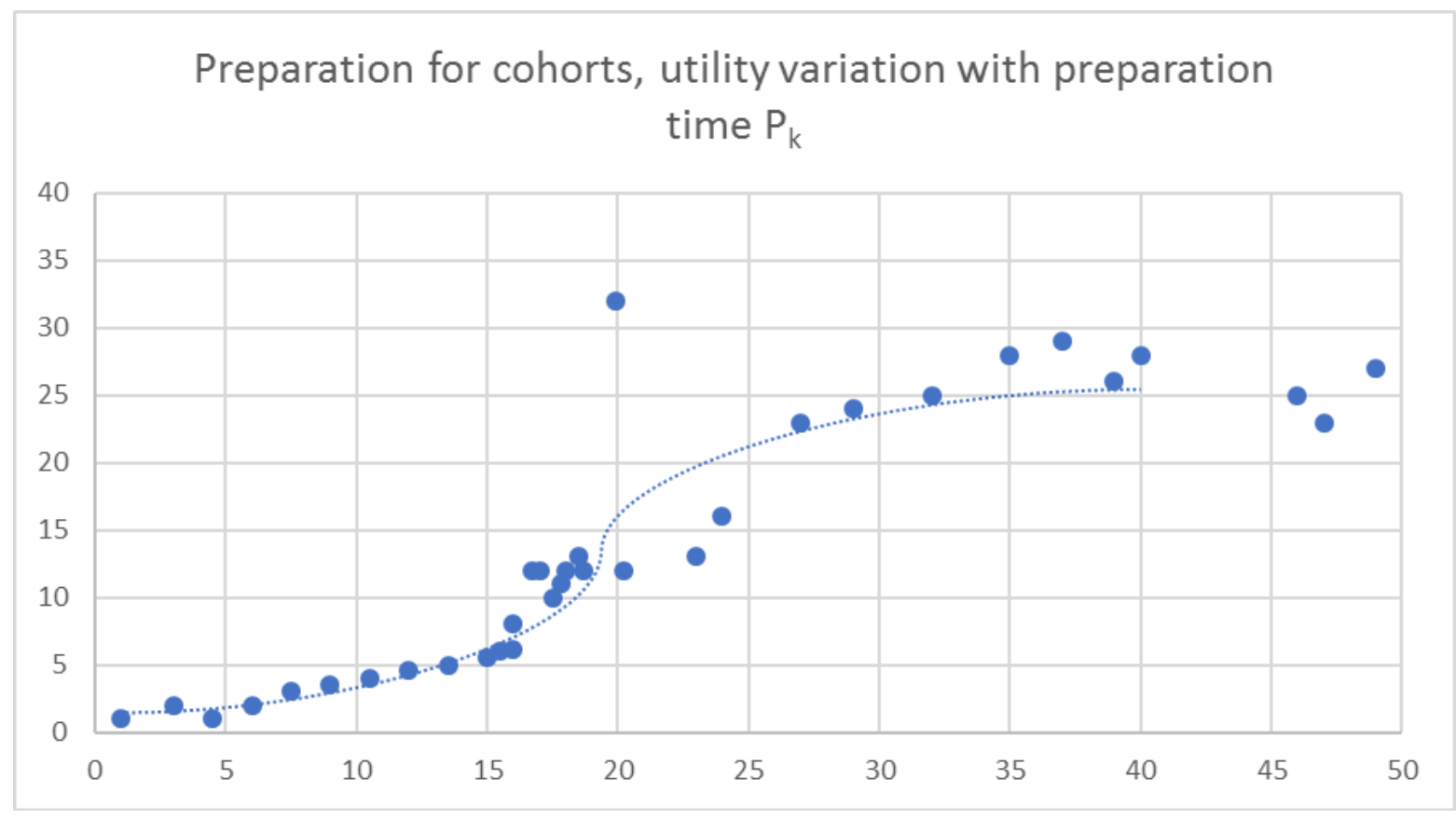

Company specific preparation, again, follows a logarithmic trend. However, the values must not be negative if no effort is put, hence this has been taken care of in the empirical relations developed. (This is because a log function has negative values between 0 to 1 , hence the time invested has been appropriately scaled to be greater than 1, by using 1+ variable, instead of just variable). There was a consensus of company specific preparations among the members of the focussed group discussion and even the data supplied by the survey respondents also rendered the scatter plot of comparatively healthy behaviour Still, it is worth noting that the R-square value is not close to 1 because of the low sample size and many other determinants (availability of materials for preparing for a particular firm) that have been ignored for simplification.

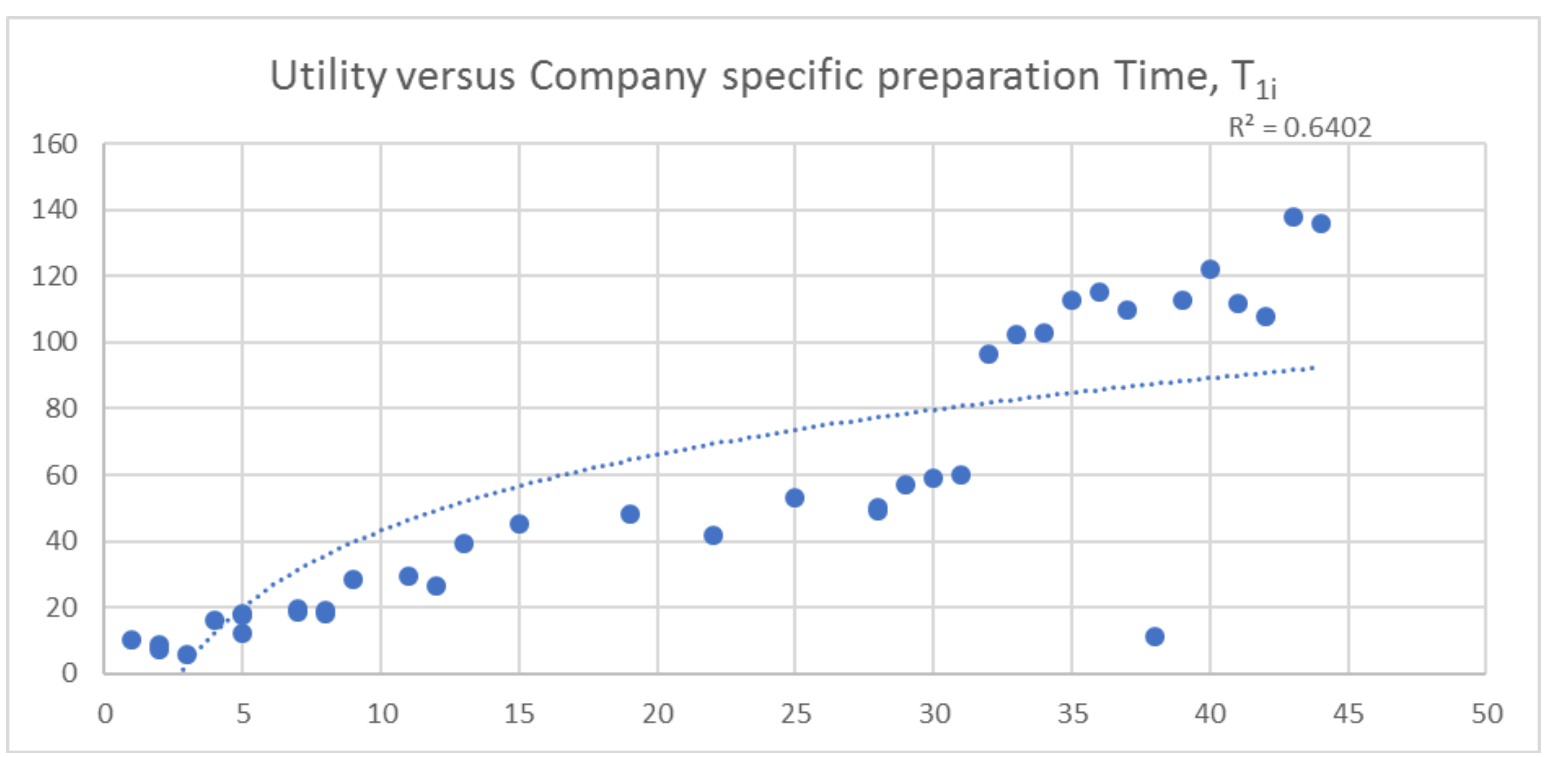

The scatter plots have been created to provide a backing to the idea about, and the systematic procedure involved in generating the empirical equations. Now let us see the equation for $\mathbb{\Gamma}_{1}$ in detail, and understand each term sincerely. Consequently, we shall see if that understanding can provide us some systematic method of analysing whatever decision we could have taken by students. We shall try to define the sub-game situation that a candidate goes through during analysed period and try to resolve the same using the developed relationships.

Before the decision tree analysis, let us discuss about few aspects of decision making which do not pertain to the decision tree. For example, how much time to allocate to competition, group task, individual evaluations, placement preparations and competitions needs to be decide. This has been found upon the LFCI (interviews with students) that the first year students have very less chance of winning in competitions in which PGP-2 also participate. We collected the data for last 23 case competitions and found that PGP-2 members were directly or indirectly involved in $\mathbf{7 3 . 9 \%}$ of the winning cases. Hence, it is recommended that after the CV gets frozen, the students are not advised to spend time in competitions. Similarly, it was found that benefit from devoting time to 
club activity post $\mathrm{CV}$ freeze in the analysed period is negligible and a rational student thinking purely from these objectives would refrain from them.

Additionally, it has been established that students should devote minimum possible time to the group tasks because the lesser the time given to group task, the more will be the time devoted by the other members of the group to compensate for that loss. This creates two-way benefit for the student from a mathematical point of view. She gets more time $T_{i}$ available, while others value of $\mathbf{T}_{\text {iy }}$ reduces in a competitive domain $(y=$ another student). Similarly, it is advised that students should devote moderate amount of time to academics during this period as it will have only moderate effect on the ultimate goal as defined earlier. Finally, the students should devote maximum possible time towards preparation for summer placements while taking adequate rest and leisure, as internship is found to have the most significant impact among all the predictors, on the ultimate goal as defined earlier.

\section{Decision Tree and Analysis of sub-games}

For any cohort $\mathrm{k}=1,2,3,4$ the student $\mathrm{j}$ shall go through the typical decision making process as shown in the flowchart below. The square boxes denote 'decision nodes' i.e. the actions that are to be taken by the student by taking a decision by himself or herself. The circles denote 'chance nodes' i.e. the probabilistic event that the student has to observe whatever happens and then respond accordingly. The dotted boxes contain multiple choices at times, which mean that the next action or chance shall apply to all such choices.

A student ' $\mathrm{j}$ ' has to finally take the most crucial decision at the action node where she is trying to figure out:

(a) Whether to participate in cluster-1

(b) Or else, do not participate in cluster-1 \& go to cluster-2

This is the subgame situation that the student is encountering marked as "subgame of interest". However, the decisions at the subgame shall be dependent on the events preceding the same, which has been mathematically framed using the notations and definitions discussed earlier.

\section{See decision tree in the next page.}




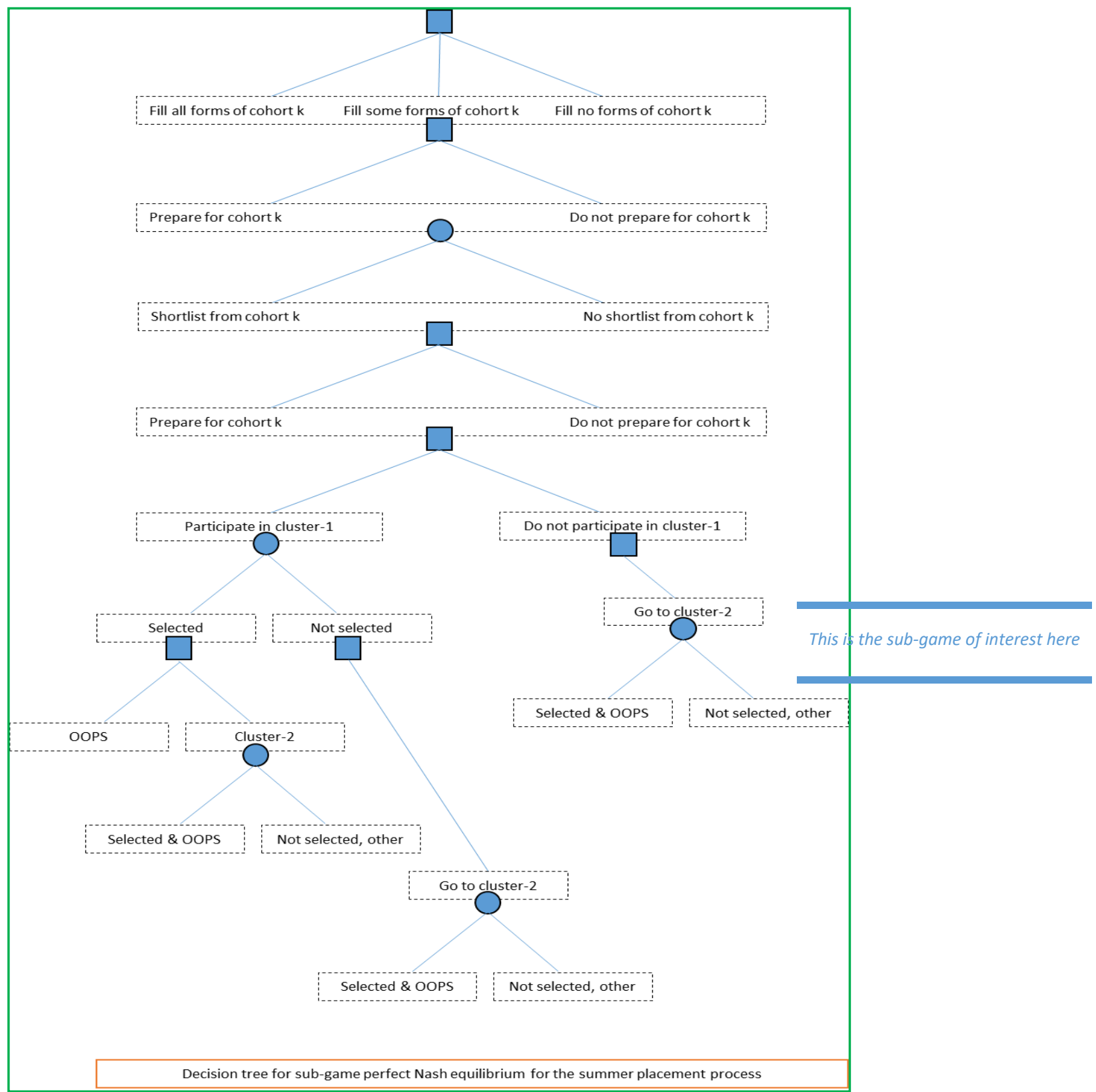

At the decision node of 'whether or not to participate in cluster' i.e. at the sub-game of interest, the utility function as describe above having one portion of utility derived from the summer intern has been used for building inequalities aimed at providing a logical decision.

In plain terms, a rational student will take part in cluster 1 only if the following condition gets satisfied: Benefit by participating in cluster 1 - benefit in cluster 2 by not participating in cluster $1>0$

Using the earlier derived equations, this can be translated into mathematical terms as follows.

We have, utility $\mathbb{\Gamma}_{1}$ defined as:

$$
\begin{aligned}
\mathbb{\Gamma}_{1}=\frac{\left[\left(D_{4}\left[\sum b_{1 i} D_{1 i} \log \left(1+T_{1 i}\right)\right] *\left[\left(P_{1}+Q_{1}+K_{1}\right)^{\frac{1}{3}}+K_{2}\right]\right)\right]}{(P+Q)_{\max }} \\
+\frac{\left[\left(D_{4}\left[\sum b_{2 i} D_{2 i} \log \left(1+T_{2 i}\right)\right] *\left[\left(P_{2}+Q_{2}+K_{3}\right)^{\frac{1}{3}}+K_{4}\right]\right)\right]}{(P+Q)_{\max }} \\
+\frac{\left[\left(\left[\sum b_{3 i} D_{3 i} \log \left(1+T_{3 i}\right)\right] *\left[\left(P_{3}+Q_{3}+K_{5}\right)^{\frac{1}{3}}+K_{6}\right]\right)\right]}{\left(1+D_{4}\right)^{\alpha}} \\
+\frac{\left[\left(\left[\sum b_{4 i} D_{4 i} \log \left(1+T_{4 i}\right)\right] *\left[\left(P_{4}+Q_{4}+K_{7}\right)^{\frac{1}{3}}+K_{8}\right]\right)\right]}{\left(1+D_{4}\right)^{\alpha}}
\end{aligned}
$$


For uniformity in analysis, let us assume that firm specific preparation constitutes a relatively constant amount of time as far as all the preparations are concerned. The effect of the firm specific preparation has no variable effect as such in the forthcoming analysis. The inequality for decision making described above, thus becomes:

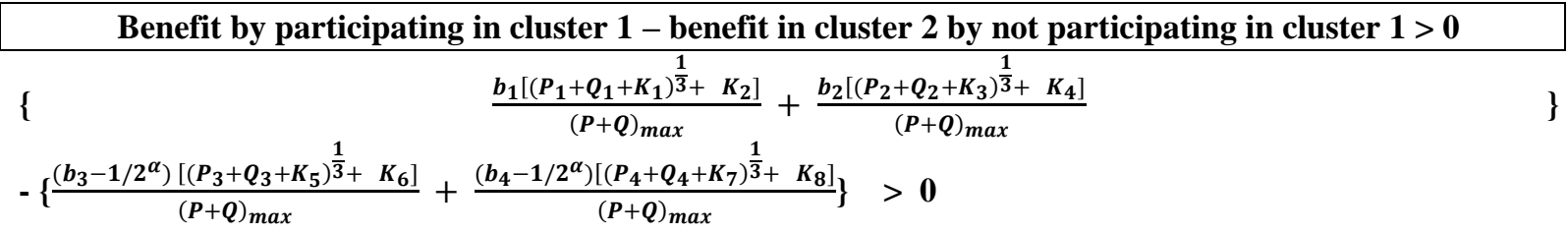

Decisions based on sub-game dilemmas

Upon interviewing (LFCI) of PGP-2 students about their past internship placement process we found that the decision to participate in a cohort or a cluster is strongly governed by a combination of preference for a cohort such as marketing, and the relative strength of the student for that cohort ie the marketing nerd. This combination of preference and relative strength is what has been shown in the equation in the form of $b_{1}, b_{2}, b_{3}$, $\mathrm{b}_{4}$ as coefficients.

The values that $b$ attains is significantly different for each cluster, and the diminishing impact due to the fatigue generated by cluster- 1 process is very miniscule, as established by those members of FGD who participated in cluster-2. Moreover, it was found that if a student prepares only for a single cluster, the marginal benefit derived from the additional time devoted is not significant after a certain duration of time as analysed in the graph as well. However, a student would also not be able to prepare for any cohort well if he tries to extend this logic and study for three or more cohorts.

Hence, the rational decision about whether or not to participate in custer-1 will be based on top two cohorts for which the student perceives himself as most suitable. (based on the value of $b_{k}$ - i.e. the combination of preference and relative strength).

In a similar manner, sequentially analysing the sub-game tree at the previous decision node i.e. just after the shortlist arrive and for which cohorts to prepare for shall be decided. Here also, the rational decision will be to study for two cohorts from which the student has got shortlist based on the values of $b_{k}$ for different cohorts, and also the preparations done till that point of time.

Similarly, proceeding back in the tree will mean the decisions should be taken even when the shortlists are not out as the time of preparations is limited. Hence, in the previous decision node, we need to decide which cohorts to prepare for before the shortlists are released. Here doing the similar mathematical exercise, the expected utility will be maximised by studying for the cohort which has highest value of $b_{k}$. As such, the student is advised to prepare for prepare for just one cohort before the shortlists are out.

Further, we reach to the top decision node i.e. where we need to decide which all forms are to be filled. Here, based on a similar mathematical exercise and comparison of coefficients, a rational student should fill all forms of Finance \& Consulting roles based on $\sum \mathbf{d}_{\mathbf{i}}$ summated for these two cohorts i.e. because the forms of consulting and finance are very short and doesn't take much time to be filled. Contrarily, firms offering markeing and general management roles have very long forms to be filled which can take hours of concentrated effort per form. These must be filled only if the $b$ value of the specific cohort is high in the proportions so as to negate the effect of longer form filling time i.e. $\sum \mathbf{d}_{\mathrm{i}}$. i.e $\operatorname{Effect}(\mathrm{b})>\operatorname{Effect}\left(\sum \mathrm{d}_{\mathrm{i}}\right)$.

This concludes our analysis of sub-games involved for any student $\mathrm{j}$ in the summer placement process. For concluding the above mathematical solutions in consonance with the stated decision dilemmas that a student encounters, it is imperative to visit back each of the dilemmas and analyse their optimal solution as done in the next section.

\section{Conclusion}

As most of the recommendations have been presented s and when the scenario has been analysed, the key message can be collated in the form of these five decisions with which the whole research had been started.

Decision 1: Which all companies' forms to fill?

Fill the forms of consulting and finance roles as they take negligible time, and fill the forms of marketing and general management roles based on the empirical criteria described above which can be interpreted as follows: If the impact combination of cohort preference and relative strength for it offsets the loss of time required in duly filling the forms, then only fill the forms for these cohorts. 
Decision 2: Which all cohorts to prepare for?

Before the shortlist are out, an analysis of the sub-game tree reveals that the student should rationally prepare for exactly one cohort, and after the shorts are out she should prepare for exactly two cohorts which are falling higher in priority based on comparing the coefficients of the preference of cohorts and the relative strengths.

Decision 3: Which all firms to prepare for?

It has been established that this decision shall remain subjective to the variables as coefficients (instead of constants), hence a qualitative decision should be taken s follows: Only after the shortlist is announced, should a student start firm specific preparation, based on the two cohorts he has been preparing for, and his preference order.

Decision 4: Should a student participate in cluster-11?

This is the heart of sub-game perfect Nash equilibrium analysis, as shown in the tree. This decision has to be governed only by the two cohorts for which the student has been preparing, after the shortlists were announced. Decision 5: How to allocate time between different activities during the analysed period?

The student is recommended to not invest time in competitions, allocate minimum possible time to club activities and group tasks, devote moderate time for individual evaluation, and invest maximum possible proportion of time for placement preparation while taking adequate rest.

\section{References}

[1] The Effective Use of Student Time: A Stochastic Frontier Production Function Case Study Peter Dolton, Oscar D. Marcenaro and Lucia Navarro, retrieved from : http://cee.lse.ac.uk/ceedps/CEEDP10.pdf

[2] Effects of Employment on Student Academic Success Compiled December 2006 Updated December 2016 BYU Employment Services retrieved from : https://www.byu.edu/hr/sites/default/files/effects_of_student_employment.pdf

[3] Placement process at IIM Ahemdabad, 2016 Report, https://web.iima.ac.in/iprs/gallery/PGP_IPRS\%20Audited\%20Report_2016.pdf

[4] Work experience and learning: a case study of MBA students Ahmad Sharbatoghlie Sharif University of Technology, http://www.aabri.com/manuscripts/11763.pdf

[5] Risk Theory and Student Course Selection, Dennis Zocco, University of San Diego, Research in Higher Education Journal - Volume 3

[6] Symmetric Subgame-Perfect Equilibria in Resource Allocation, Journal of Artificial Intelligence Research 49 (2014) 323-361 